\title{
Análise do impacto das variações institucionais européias sobre a governança do sistema agroindustrial brasileiro da carne bovina*
}

\author{
Mariusa Momenti Pitelli** \\ Márcia Azanha F. Dias de Moraes***
}

Resumo: O presente artigo tem por objetivo verificar os impactos das mudanças no ambiente institucional, europeu e nacional, em virtude das exigências do consumidor europeu quanto à qualidade do produto, sobre o Sistema Agroindustrial Bovino nacional. Os resultados indicam que embora o aumento das exigências dos consumidores europeus tenha alterado o ambiente institucional do bloco, com conseqüentes alterações no ambiente institucional brasileiro, houve pouco impacto sobre a forma de governança das transações do SAG da carne bovina nacional. Na relação da indústria frigorífica exportadora com o fornecedor de boi, verificou-se que não há estabelecimentos de contratos nas transações, que pode ser explicado pela credibilidade entre as partes no que tange ao pagamento e à entrega de bois, e também pela falta de enforcement (aplicação das regras) da rastreabilidade por parte da UE e do governo brasileiro (o que reduz a especificidade do ativo da matéria-prima). Quanto à relação do frigorífico com seus compradores do mercado interno prevalece um compromisso confiável entre as partes, sendo as transações conduzidas via mercado. No que se refere às relações dos frigoríficos exportadores com o mercado europeu, o aumento da especificidade dos ativos conduziu ao estabelecimento de contratos como forma de diminuir seus custos de transação.

*Baseado na dissertação de mestrado da primeira autora, com financiamento da CNPq, orientado pela segunda autora.

**Doutoranda em Economia Aplicada pela ESALQ/USP. mpitelli@esalq.usp.br

***Doutora e Professora da ESALQ/USP. mafdmora@esalq.usp.br 
Palavras-chave: carne bovina, ambiente institucional, estrutura de governança

Classificação JEL: D23, D21, L22, L23

Abstract: The present work aims to analyze the changes in the institutional environments, European and National, due to European consumers' requirements regarding the quality of products, about the $\mathrm{Na}$ tional Beef Agro-Industrial System. The results indicate that despite the rise on requirements from European consumers, which has changed the institutional environment of the block, with consequent changes in the Brazilian institutional environment, there has been little impact on the governing procedures of transactions of SAG of domestic beef. Regarding the relationship between beef export slaughterhouse industry and beef suppliers, it was verified that there are no establishments of agreements for the transactions, that this fact can be explained through the creation of reliable commitments between the parts, as for the paying and delivery of cattle, and also by the lack of enforcement on traceability on the part of the European Union and the Brazilian government (which reduce the peculiarity of the assets of the raw material). As for the relationship between the slaughterhouse and its consumers of the domestic market, a reliable commitment prevails between the two parties, being the transactions conducted through the market. Regarding the relationship between the export slaughterhouse and the European market, the rise on the peculiarity of assets leads to the establishment of agreements as a way to reduce the costs of transactions.

Key words: beef, institutional environment, governing framework.

JEL Classification: D23, D21, L22, L23

\section{Introdução}

O Sistema Agroindustrial (SAG) brasileiro da carne bovina está enfrentando um processo de evolução, em que as empresas, pressionadas 
pelo aumento de competição, estão se reestruturando para obterem ganhos de produtividade e qualidade.

Em 2004, a produção de carne bovina foi de 7,830 milhões de toneladas em equivalente carcaça, e um consumo interno de 6,415 milhões de toneladas em equivalente carcaça. Quanto ao comércio internacional, verificou-se uma importação de 63 mil toneladas em equivalente carcaça e uma exportação no valor de 1,470 milhões de toneladas em equivalente carcaça, com tendência crescente ao longo dos últimos anos. (Estados Unidos, 2005).

Com o anúncio, em 1996, da relação entre a Encefalopatia Espongiforme Bovina (EEB) ou doença da "vaca-louca" e a doença em humanos Creutzfeldt-Jakob (CJD), aumentou-se a preocupação dos consumidores, principalmente o europeu, quanto à qualidade do produto e segurança do alimento. A partir disso, a União Européia introduziu leis sanitárias rigorosas aos produtos cárneos.

Como a UE é o maior importador de carne bovina brasileira (aproximadamente $41 \%$ do valor total de carne bovina brasileira exportada em 2003, conforme Brasil, 2004), as exigências impostas trouxeram a necessidade de um processo de reestruturação ao longo de toda cadeia de carne bovina no Brasil, incluindo ações dos agentes privados e do governo, implicando alterações no ambiente institucional brasileiro para viabilizar a implantação de um sistema rigoroso de rastreabilidade dos produtos cárneos, visando a manutenção da segurança do alimento e aumento da competitividade.

Assim, considerando-se que a União Européia é o maior mercado importador de carnes do Brasil e o fato deste país ter um grande potencial em expandir suas exportações, o estudo sobre os impactos das exigências dos consumidores europeus sobre a coordenação da cadeia produtiva e sobre as estruturas de governança torna-se tema relevante de trabalho.

O objetivo geral deste trabalho é verificar os impactos de mudanças no ambiente institucional, europeu e nacional, sobre o Sistema Agroindustrial Brasileiro da Carne Bovina. Tem como objetivos específicos: fazer uma caracterização geral das empresas frigoríficas exportadoras; identificar as principais exigências do consumidor europeu quanto à qualidade do produto; apontar as principais mudanças relevantes no ambiente institucional e organizacional brasileiro e europeu com possí- 
veis impactos ao SAG; analisar se a variação de especificidade do ativo está alterando a estrutura de governança nos seguintes elos: frigorífico e fornecedor de boi, frigorífico e varejo (mercado interno) e, frigorífico e mercado europeu.

A hipótese deste trabalho é que a alteração no ambiente institucional, devido principalmente às exigências do consumidor europeu, aumenta a especificidade do ativo, levando à adoção de uma estrutura de governança mais restrita como forma de reduzir os custos de transação, em ambiente de oportunismo e racionalidade limitada.

\section{Referencial Teórico}

O presente artigo utiliza-se dos conceitos fundamentais da Nova Economia das Instituições (NEI), em suas vertentes denominadas de Ambiente Institucional e de Instituições de Governança.

A utilização da ECT como base analítica para o estudo das formas organizacionais da produção busca relacionar as dimensões típicas das transações com as formas de organização mais eficientes em termos de economia nos custos de transação e produção, em que a análise comparativa implica o contraste entre formas alternativas de organização, desde a realização da produção via mercado até o outro extremo, que é a verticalização.

Os pressupostos comportamentais - racionalidade limitada e oportunismo - juntamente com as dimensões das transações - especificidade do ativo, incerteza e freqüência - determinam a estrutura de governança eficiente, sendo a especificidade do ativo a variável-chave, pois quanto mais específico for o ativo, a adoção de relações hierárquicas torna-se mais eficiente. Segundo Zylberzstajn (2004), quando a especificidade dos ativos é baixa, a transação pode acontecer no mercado, pois não há necessidade de forte controle sobre ela. Mas, à medida que a especificidade dos ativos aumenta, o mercado passa a ser uma solução ineficiente, sendo necessário maior controle, através da integração vertical ou contratos com salvaguardas específicas.

O Quadro 1 relaciona os pressupostos comportamentais frente às especificidades do ativo com a forma contratual redutora de custos de transação. 
Quadro 1 - Atributos do processo de contratação*

\begin{tabular}{|c|c|c|c|}
\hline \multicolumn{2}{|c|}{ Pressupostos Comportamentais } & \multirow{2}{*}{$\begin{array}{c}\text { Especificidade } \\
\text { Ativo }\end{array}$} & \multirow{2}{*}{$\begin{array}{l}\text { Processo de } \\
\text { Contratação }\end{array}$} \\
\hline $\begin{array}{l}\text { Racionalidade } \\
\text { Limitada }\end{array}$ & Oportunismo & & \\
\hline 0 & + & + & $\begin{array}{l}\text { Planejamento } \\
\text { (capacidade de previsão } \\
\text { de todos os problemas) }\end{array}$ \\
\hline+ & 0 & + & $\begin{array}{l}\text { Promessa (baseado na } \\
\text { honestidade das partes) }\end{array}$ \\
\hline+ & + & 0 & Mercado \\
\hline+ & + & + & Relações hierárquicas \\
\hline
\end{tabular}

Fonte: Williamson (1989)

* “+” indica presença do atributo, e “0” indica ausência do atributo.

De acordo com o Quadro 1, no caso em que as partes tenham racionalidade total, mas são oportunistas e os ativos são específicos, todos os aspectos pertinentes do contrato se esclarecem na etapa da negociação ex-ante, assim, sugere-se o planejamento. Nesse caso, os contratos seriam completos, uma vez que os agentes seriam todos racionais e poderiam prever todas as situações ex-ante. Na situação em que os agentes não são oportunistas, mas a racionalidade é limitada e tem-se a presença de ativos específicos, a simples promessa (acordo tácito) entre as partes seria suficiente para não se aproveitarem da incompletude dos contratos, contornando a dependência bilateral entre as partes gerada pela especificidade do ativo. No caso em que há ausência de especificidade, mas há racionalidade limitada e oportunismo, é eficaz a contratação discreta via mercado, pois os ativos podem ser livremente deslocados entre suas utilizações. Na situação com racionalidade limitada, oportunismo e especificidade dos ativos, as relações hierárquicas seriam indicadas para minimizar os custos de transação envolvidos. Nota-se que a especificidade do ativo só tem importância na presença de racionalidade limitada e oportunismo, sendo estes os dois pilares da ECT.

Em relação ao ambiente institucional, North (1993) afirma que o mesmo não é neutro no processo de desenvolvimento econômico, devendo ser considerado endógeno ao modelo. Segundo o autor o ambiente institucional é composto pelas regrais formais e informais de uma sociedade.

North (1993) expõe que as organizações desenvolvem-se dentro do 
ambiente institucional, sendo assim, limitadas e condicionadas pelas regras institucionais, porém, as instituições são da mesma forma afetadas pelas organizações. De acordo com o autor, para que as regras e comportamentos desejados sejam cumpridos, é necessário que haja algum mecanismo de enforcement (ou seja, fazer valer as regras) capaz de assegurá-las e conduzi-las através do tempo.

O modo eficiente de governança resultará, portanto, da interação entre o ambiente institucional, o comportamento dos indivíduos e das características das transações.

\section{Metodologia}

Adicionalmente à pesquisa bibliográfica, houve a necessidade de levantamento de dados primários, via aplicação de questionários direcionados às empresas frigoríficas de carne bovina que possuem Sistema de Inspeção Federal (SIF) e que são habilitadas a exportar para a União Européia, como forma de entendimento e maior explicitação dos principais aspectos relacionados à variação da estrutura de governança das transações.

A pesquisa foi realizada com os frigoríficos pertencentes à Associação Brasileira das Indústrias Exportadoras de Carne (ABIEC), que totalizam atualmente 18 grupos frigoríficos, e representavam, em 2003, 84 \% do valor das exportações totais do Brasil. Foram enviados questionários a todos os frigoríficos da ABIEC, e realizadas três entrevistas. A obtenção de dados primários está relacionada à necessidade de informações sobre o modo de governança das transações dos frigoríficos exportadores, para poder, então, atender aos objetivos estabelecidos neste trabalho. O percentual de respostas representou $53 \%$ da amostra, sendo os dados obtidos submetidos a uma análise estatística.

Cabe ressaltar a limitação da amostra aos frigoríficos exportadores, porém são nestes em que se refletem as prováveis alterações no ambiente institucional.

Os principais módulos que compõem os questionários são denominados respectivamente por características gerais, aspectos institucionais e organizacionais, relação com o fornecedor, relação com o varejo 
e relação com clientes europeus. As variáveis que compõem o questionário estão descritas em Pitelli (2004).

\section{Resultados e Discussão}

A seguir são apresentados os resultados dos questionários e entrevistas realizadas com as nove empresas frigoríficas exportadoras para a União Européia, em que a discussão e análise serão feitas seguindo os módulos do questionário.

\subsection{Características gerais}

Quanto à caracterização geral das empresas, 100\% das nove que participaram da pesquisa, são de capital nacional, a maioria são empresas familiares, em que o faturamento anual destas empresas variam de menos de R\$ 300 milhões até para mais de R\$ 1 bilhão. É interessante notar a ausência de capital estrangeiro na indústria frigorífica, a despeito das baixas barreiras à entrada existentes (requerimentos de capital). Este fato pode ser explicado pela presença do mercado clandestino de carnes, o que funciona como uma barreira è entrada de empresas estrangeiras, ao tornar a competição entre as empresas formais (incluindo-se aí as possíveis entrantes de capital externo) e informais desleais. Ressalta-se que na região sudeste (mais Mato Grosso do Sul), onde se localiza a maior parte dos frigoríficos exportadores, bem como na região sul, observa-se um grau mais elevado de abate clandestino, devido a prováveis estímulos de mercado e/ou por razões de evasão fiscal.

Observa-se que as empresas foram fundadas em diversas décadas, ou seja, os tempos de exercício no mercado são muito distintos, sendo a maioria, 33,3\%, fundadas na década de 1970 .

Das nove empresas pesquisadas, $100 \%$ atendem tanto o mercado interno quanto o mercado externo, o que pode ser explicado pela necessidade de ajuste ou arbitragem dos volumes/receitas entre o mercado externo e interno das empresas, para conseguirem fechar suas contas no final de cada período.

A maioria das empresas iniciou suas exportações aos clientes externos a partir da década de 1990, e em relação aos seus clientes externos, 
Análise do impacto das variações institucionais européias sobre a governança do sistema agroindustrial brasileiro da carne bovina

nota-se que das nove empresas, $100 \%$ exportam para a UE, $100 \%$ para o Oriente Médio, $100 \%$ para a Ásia, 33,3\% para os EUA e $77 \%$ exportam para outros países, dentre eles África (Costa Marfim, Argélia), América do Sul (Chile, Peru), Rússia, Canadá. Nota-se que as empresas possuem uma diversificação de mercados, atendendo clientes praticamente em todos os continentes. A participação das empresas no mercado norte-americano é pequena devido ao fato deste país só importar carne industrializada do Brasil, por não reconhecer regiões brasileiras livres de febre aftosa.

\subsection{Aspectos institucionais e organizacionais}

Esta seção tem como objetivo analisar as mudanças organizacionais e institucionais e conhecer os programas de qualidade exigidos pelos clientes e o comportamento da empresa frente a essas exigências.

Quanto à participação da empresa em alianças mercadológicas ou programas de novilho precoce, $71,4 \%$ de sete empresas participam de Programas de Novilho Precoce ou de Aliança Mercadológica, fornecendo uma carne de melhor qualidade aos clientes e obtendo em troca um preço maior, e apenas $28,6 \%$ não participam. Ressalta-se que a participação em Programa de Novilho Precoce ou Alianças Mercadológicas possibilita uma maior coordenação da cadeia, e adoção de relações mais hierárquicas, a fim de que as exigências de qualidade sejam cumpridas.

Em relação à responsabilidade da coordenação da cadeia de carne bovina, $42,9 \%$ de sete empresas consideram que é do governo, por ter condições em dar incentivos via impostos (ICMS), por ter meios para coordenar e inspecionar, e por ter uma neutralidade de interesse. Por sua vez $28,6 \%$ disseram que a responsabilidade deve ser dos frigoríficos exportadores, por terem melhor conhecimento do negócio; $14,3 \%$ consideram que os pecuaristas são os responsáveis, por estarem mais próximos do "produto", podendo dessa forma coordenar de perto a criação e venda do boi e $14,3 \%$; responderam que devem ser os frigoríficos em geral.

Em relação à rastreabilidade, das nove empresas pesquisadas todas têm um determinado nível: 77,8\% possuem rastreabilidade parcial, 
ou, seja, iniciada com o animal já vivo, sendo implantada tanto na recria quanto na engorda, e 22,2\% adotam rastreabilidade total, que é iniciada no nascimento do animal. Dentre as empresas que possuem rastreabilidade parcial, algumas responderam que já abatem quase que $100 \%$ de animais totalmente rastreados, assim, logo terão um nível de rastreabilidade total.

Observa-se que das nove empresas que responderam a questão, todas adotam rastreabilidade, HACCP (Análise de Perigos e Pontos Críticos de Controle - sistema que permite identificar, avaliar e controlar perigos que comprometem a sanidade dos alimentos), BPF (Boas Práticas de Fabricação - procedimentos necessários para assegurar alimentos inócuos e saudáveis), e 22,2\% adotam ISO 9000 (estabelece os requisitos para assegurar a qualidade dos processos de produção). Cerca de 88,9\% das nove empresas adotam outros programas, como PPHO (Procedimento Padrão de Higiene Operacional evita a contaminação direta ou cruzada ou adulteração dos produtos através das superfícies dos equipamentos, utensílios, instrumentos de processo e manipuladores de alimentos), POP (Procedimentos - Operacionais Padronizados), Programa de Controle de Organismos Geneticamente Modificados (OGM), Programa de Abate Humanitário (dentro dos padrões do bem-estar animal). Porém, vale mencionar que as BPF e PPHO são pré-requisitos essenciais para a implantação do HACCP, portanto, nota-se que há uma incoerência nas respostas, pois todas dizem que adotam HACCP mas nem todas adotam PPHO.

Assim, observa-se que houve um aumento importante da especificidade dos ativos das empresas frigoríficas, principalmente do ativo carne bovina quando comparado à carne bovina commodity. Cabe destacar que nem todos os países exigem esses programas de qualidade, que demandaram investimentos específicos por parte das empresas. Portanto as empresas terão uma perda de renda se precisarem exportar para países que não os exigem ou se precisarem escoar sua produção para o mercado interno, que remunera menos que o externo e não exige a rastreabilidade (pela nova instrução normativa de $\mathrm{N}^{0} 77$, de 2004, a adoção da rastreabilidade não é mais obrigatória para a venda da carne bovina no mercado nacional).

Todos os clientes europeus das nove empresas pesquisadas exigem HACCP, 77,8\% das empresas disseram que seus clientes exigem BPF e 
Análise do impacto das variações institucionais européias sobre a governança do sistema agroindustrial brasileiro da carne bovina

no que diz respeito à rastreabilidade, $33,3 \%$ das empresas têm como exigência a rastreabilidade total e $66,7 \%$ têm como exigência a rastreabilidade parcial.

Em relação ao ano de exigência desses programas de qualidade pela UE, observa-se que o ano em que os clientes europeus exigiram determinados programas de qualidade corresponde ao mesmo ano de suas implementações na empresa, o que evidencia que os frigoríficos adequaram a estrutura tecnológica e produtiva com o padrão internacional, para não perderem seus clientes europeus.

Ressalta-se que embora muitas empresas digam que compram bois com rastreabilidade total, a grande parte dos pecuaristas que dizem possuir bois com esta especificidade na verdade podem não a possuir, ou seja, podem estar vendendo um boi com rastreabilidade parcial (ou mesmo não rastreado), como se fosse um produto com rastreabilidade total, pelo fato de não conseguirem seguir rigidamente as normas estabelecidas no SISBOV. Este fato a mostra a necessidade de um maior enforcement por parte da UE e do governo brasileiro sobre os frigoríficos e pecuaristas. Assim, essa falta de enforcement conduz ao pequeno aumento da especificidade, e, portanto, ao pequeno aumento dos custos de transação, o que pode levar a não adoção de contratos formais.

No que se refere às exigências do cliente europeu quanto à matériaprima boi, de oito empresas, $100 \%$ têm como exigência a não utilização de hormônios, $62,55 \%$ a não utilização de ingredientes de origem animal, 62,5\% a não utilização de antibióticos (pode usar desde que respeite a quarentena antes do abate e utilize antibióticos controlados e aprovados pelo MAPA e pelos países importadores) e 12,5\% das empresas responderam que há outros tipos de exigências. Essas exigências tornam o boi um ativo cada vez mais específico.

\subsection{Relação com o fornecedor}

Esta seção se refere ao relacionamento das empresas frigoríficas com seus fornecedores de boi, em que se pretende verificar se a especificidade do ativo está alterando as formas de governança desta transação.

A Tabela 1 traz informações sobre a forma como o frigorífico adquire o boi. 
Tabela 1 - Forma de adquirir a matéria-prima boi

\begin{tabular}{lcc}
\hline & Compra de boi antes de $\mathbf{1 9 9 6}$ & Compra de boi atualmente \\
\hline & Percentagem & Percentagem \\
Via mercado & $100 \%$ & $100 \%$ \\
Via contrato & 0 & 0 \\
Outro modo & 0 & 0 \\
TOTAL & $100 \%$ & $100 \%$ \\
\hline
\end{tabular}

Fonte: dados da pesquisa

Observa-se que das oito empresas que responderam esta questão, todas compram boi via mercado, tanto antes de 1996, como atualmente, quando se amplificaram as exigências quanto à segurança do alimento. A compra é feita por um comprador próprio da empresa que vai até o produtor ou por telefone, e somente há uma ordem de compra, sendo os critérios de compra pré-estabelecida como, por exemplo, rastreabilidade, raça, peso e castração. Ou seja, embora não exista um contrato formal, as exigências do produto são estabelecidas e devem ser cumpridas.

Os dados da pesquisa revelam que as empresas compram boi diariamente de seus fornecedores, ou seja, a compra de boi, bem como sua negociação, é um processo que se repete todos os dias. Percebe-se que na maior parte dos frigoríficos há uma manutenção de seus fornecedores todo ano, mas sempre acabam agregando novos fornecedores. Assim, essa constância de fornecedores possibilita a criação de uma relação de credibilidade entre pecuarista e frigorífico, que também explica a pouca incidência de contratos formais entre as partes.

As empresas pagam à vista, em que geralmente cobram um desconto de $4 \%$, ou para 30 dias sem desconto. Há concorrência de empresa que possui sistema de controle de abate on-line via Internet, onde os pecuaristas têm acesso a várias informações sobre os animais encaminhados ao abate, aumentando a confiança entre fornecedor de boi e frigorífico.

Em relação à criação de boi para fornecimento próprio, 87,5\% de oito empresas, cria boi para fornecimento próprio, ou seja, se verticaliza para trás, e apenas $12,5 \%$ não cria boi. Quanto ao motivo dessa integração, apenas cinco empresas responderam, onde $60 \%$ destas responderam que se integram para terem maior controle da qualidade e da 
rastreabilidade do boi, retratando o aumento da especificidade do boi, $20 \%$ devido à garantia da oferta de boi na entressafra e $20 \%$ responderam ambos.

Observa-se que os frigoríficos obtêm boi via compra no mercado bem como criando boi para fornecimento próprio. Dessa forma, prevalece uma estrutura de governança mista, regida tanto pelo mercado, que é caracterizado pela credibilidade entre o frigorífico e o pecuarista, como pela verticalização para trás dos frigoríficos.

No que se refere ao incentivo dado pela empresa na compra de boi rastreado, das sete empresas que responderam, 85,7 \% destas dão como incentivo o preço, e apenas $14,3 \%$ dão outro tipo de incentivo, como o oferecimento de brincar os bois para o pecuarista. Porém, atualmente o estímulo econômico para rastrear é baixo, pois o prêmio é muito pequeno.

No que se refere às incertezas das transações, percebe-se que em relação ao aumento do preço do boi verifica-se que não há uma tendência clara, já que os graus de incerteza altos e baixos tiveram o mesmo número de repostas, além disso, algumas empresas operam no mercado futuro de boi gordo, reduzindo o risco de preço. Quanto à falta de boi para compra, a maioria das empresas tem baixa incerteza, o que pode ser explicada pelo fato de algumas empresas confinarem o gado para garantir a oferta na entressafra. Quanto à concorrência com outros frigoríficos na compra de boi, a maior parte dos frigoríficos possuem baixa incerteza, porém como todas as empresas competem com outros frigoríficos na aquisição de boi, elas utilizam estratégias como criação própria e forma de pagamento à vista, em que este beneficia a empresa pelo fato de pagar mais barato e de obter clientes fiéis. Dessa forma, as incertezas quanto à matéria-prima boi relacionadas ao ambiente econômico são consideradas baixas pela maior parte dos frigoríficos.

Em relação ao comportamento dos fornecedores, das sete empresas que responderam esta questão, todas afirmaram que há fornecedores que cumprem o estabelecido. Além disso, quatro delas $(57,1 \%)$ disseram que também possuem fornecedores que não cumprem o combinado. Porém a participação dos fornecedores que cumprem o combinado no total de casos ocorridos na empresa é maior ou igual a $90 \%$.

Observa-se que ocorre credibilidade entre pecuarista e frigorífico 
no que se refere à entrega de boi pelo pecuarista ao frigorífico na data combinada e quanto ao pagamento do boi pelo frigorífico ao pecuarista no valor estabelecido na compra, ou seja, o que foi combinado na negociação é cumprido, o que pode explicar a não adoção de contratos formais. Deve ser salientado que esta característica não é comum a todo o mercado de carnes nacional, onde, ao contrário, existem diversos problemas de confiança entre as partes.

\subsection{Relação com o cliente interno}

Esta seção tem como objetivo verificar se houve mudanças na forma de governança entre as empresas e os clientes internos.

Todas as sete empresas têm como clientes internos os supermercados/hipermercados, 85,7\% das empresas têm como clientes atacadistas, $85,7 \%$ das empresas têm como clientes as boutiques de carne e açougues, 57,1\% lojas próprias da empresa e 42,9\% outros clientes, tais como food service, distribuidores e instituições. Conforme relato das empresas, a maioria vende sua maior parcela para os supermercados/hipermercados.

Em relação à realização de contratos do frigorífico com o cliente interno, observa-se que $62,5 \%$ das oito empresas não realizam contratos, o que evidencia a credibilidade do cliente à qualidade da carne ofertada pelo frigorífico (ressalta-se que as exigências dos consumidores internos são menores) bem como a fidelidade do cliente ao frigorífico na compra da carne. Por sua vez, 37,5\% dos frigoríficos realizam algum tipo de contrato com os clientes do mercado interno.

Quanto à freqüência de vendas de carnes, a venda diária é maior que a venda semanal, o que significa que há uma alta repetição do processo de venda. Este fato torna as relações mais estáveis e possibilita um maior conhecimento entre o cliente e o frigorífico.

Observa-se que na maior parte dos frigoríficos há uma manutenção de seus clientes todo ano, mas sempre acabam agregando novos clientes. Assim, essa constância de venda para os mesmos clientes possibilita a criação de uma relação de confiabilidade entre frigoríficos e clientes internos.

No que se refere às incertezas existentes nas transações de venda 
de carne entre os frigoríficos e seus clientes, das sete empresas, 42,9\% possuem baixa incerteza quanto à queda de preço da carne de boi; $85,7 \%$ têm baixa incerteza quanto à variação na renda do consumidor interno (o que pode estar ligada ao fato desses frigoríficos terem como opção a exportação de sua carne); 42,9\% têm baixa e 42,9\% média incertezas quanto à concorrência com carne de frango e suína.

Assim, observa-se que os frigoríficos consideram que as incertezas quanto à venda da carne bovina ao cliente interno relacionadas ao ambiente econômico são na maioria baixas.

Em relação ao comportamento do cliente interno, das sete empresas que responderam esta questão, a participação dos clientes que cumprem o combinado é igual ou maior que $80 \%$. Portanto, não há um relacionamento conflitante entre o frigorífico e o mercado interno.

\subsection{Relação com o cliente europeu}

Os resultados desta seção procuram identificar aspectos das relações dos frigoríficos com os clientes europeus.

Quanto ao modo de exportação, os resultados da pesquisa indicam que $75 \%$ das oito empresas exportam tanto via traders como diretamente, e apenas $25 \%$ das empresas exportam apenas diretamente, sendo que nenhuma exporta só por traders. Os frigoríficos exportam para a UE por esta pagar preços melhores, porém, é o cliente mais exigente quanto à qualidade da carne bovina.

Quanto aos tipos de carne exportados para a UE, observa-se que $75 \%$ das oito empresas só exportam carne in natura, enquanto que apenas $25 \%$ das empresas frigoríficas exportam tanto carne in natura como industrializada (das empresas que exportam ambos os tipos de carne, a carne in natura tem uma participação maior na quantidade exportada do que a industrializada). Ressalta que os tipos de corte exportados para a UE são aqueles que possuem maior valor agregado, tais como filé mignon, contra filé, coxão mole entre outros.

Em relação aos principais clientes europeus dos frigoríficos, de sete empresas frigoríficas, $28,6 \%$ têm como clientes europeus os supermercados/hipermercados, $85,7 \%$ têm como clientes atacados, $71,4 \%$ possui como clientes empresas processadoras, $85,7 \%$ das empresas têm como 
clientes distribuidores, e 14,3\% outros clientes europeus, tais como redes de fast food. Porém, para a maioria das empresas, os distribuidores possuem uma maior participação na clientela.

Sobre as exigências serem ou não consideradas barreiras não tarifárias pelos frigoríficos, apenas 37,5\% disseram que retratam barreiras não-tarifárias, pois têm exigências de determinados clientes que não são pertinentes ou não têm fundamento técnico, tais como a exigência de animais abatidos com 30 meses (o que é difícil para o Brasil, pois os animais na maioria são criados a pasto) e de determinados procedimentos de controle de qualidade.

A totalidade das oito empresas disse que as exigências européias retratam a preocupação dos consumidores, através de legislação, o que evidencia o aumento da especificidade da carne bovina, salientando que tais exigências precisam ser cumpridas para permanecer no mercado. As principais medidas adotadas pelas nove empresas frigoríficas que participaram da pesquisa, visando ao atendimento das exigências, $100 \%$ implantaram programas de qualidade, $100 \%$ passaram a assegurar-se das fontes de fornecimento de boi, $66,7 \%$ investiram em P\&D, $66,7 \%$ contrataram mão-de-obra especializada e $11,1 \%$ adotaram outras medidas, o que mostra um aumento significativo da especificidade de ativos das empresas.

Em relação à realização de contratos, $100 \%$ de oito empresas disseram que sempre realizaram contratos de exportação com seus clientes europeus, em que nestes contratos há as especificações dos produtos de cada cliente europeu, ou seja, além de atender às exigências das legislações e às normas do país, existem exigências dos clientes para atender às necessidades específicas (peculiaridades do comprador).

Quanto à freqüência de venda de carne, observa-se que 85,7\% das sete empresas vendem diariamente a seus clientes europeus, apenas $14,3 \%$ vendem semanalmente. À medida que vão sendo honrados, novos contratos são celebrados, porém, respeitando-se as condições de mercado naquele momento.

Quanto às incertezas existentes no mercado europeu, nota-se que das sete empresas $57,1, \%$ consideram baixa a incerteza relacionada à queda de preço da carne bovina, 71,4\% têm média incerteza quanto à variação no câmbio, pois nos contratos fixam-se preços em dólar, o 
que leva muitas empresas a operarem no mercado futuro de câmbio; as incertezas quanto à imposição de barreiras sanitárias são consideradas médias $42,9 \%$ das empresas e alta por outras $42,9 \%$; e $14,3 \%$ tem incerteza média em relação a outras incertezas, como uma catástrofe sanitária.

Em relação ao comportamento do cliente europeu, das sete empresas que responderam a questão, todas afirmaram que têm clientes que cumprem o combinado. Além disso, duas delas $(28,6 \%)$ disseram que também possuem clientes que não cumprem o combinado. Porém a participação dos clientes que cumprem o combinado no total de casos ocorridos na empresa é igual ou maior que $85 \%$.

\section{Conclusões}

O aumento das exigências dos consumidores europeus quanto à segurança do alimento conduziu a mudanças no ambiente institucional nacional, e como conseqüência, aumentou o grau da especificidade dos ativos empregados nessa atividade, o que implica numa maior dependência entre os agentes.

Observou-se que os frigoríficos exportadores investiram intensivamente em programas de qualidade, para poder atender as exigências que constam nas diretivas da UE. Além de cumprirem as exigências desse bloco, os frigoríficos atendem também requisitos específicos de determinados clientes europeus, o que evidencia o aumento da especificidade da carne bovina, bem como de todos os outros ativos envolvidos na sua produção. Dentre outras medidas, cita-se a contratação de mão-de-obra especializada e investimentos em P\&D.

Dessa forma, a adoção destes programas de qualidade exigiu investimentos específicos por parte das empresas para atender a determinados requisitos, e, portanto, as mesmas terão uma perda de renda se exportarem para países que não os exigem, bem como quando têm que escoar sua produção (ou tipos de cortes específicos) para o mercado interno.

É interessante observar que embora a maioria dos frigoríficos tenha um nível de rastreabilidade parcial, alguns declararam que já abatem quase que $100 \%$ de animais totalmente rastreados, assim, logo terão um nível de rastreabilidade completa. Os frigoríficos embora reconheçam a 
dificuldade de se encontrar animais rastreados, não adotam estratégias no sentido de hierarquizar a transação via contratos com fornecedores, optando por verticalizar a produção própria de bovinos. O único incentivo dado aos pecuaristas é o pagamento de um preço maior à carne rastreada, o que não garante a oferta de animais se houver a rivalidade de outro frigorífico. Ou seja, ou não se adota uma estrutura de governança eficiente ou não se compra um boi realmente rastreado dado o baixo enforcement existente no quesito rastreabilidade.

Conforme a Economia dos Custos de Transação, a adoção de contratos de fornecimento formais entre frigoríficos e produtores de boi seria uma forma de governança mais eficiente. Contudo, duas explicações plausíveis podem ser dadas sobre a estrutura de governança adotada.

A primeira, comentada anteriormente, se refere à falta de enforcement da rastreabilidade por parte da UE e do governo brasileiro. A rastreabilidade pode não estar sendo aplicada corretamente - segundo as normas do SISBOV - pelos pecuaristas, ou seja, o pecuarista pode estar vendendo um boi não rastreado como se fosse, o que conduz ao pequeno aumento da especificidade do ativo boi, e por isso, aumentando muito pouco os custos de transação, o que explica a não existência de contratos formais.

A segunda diz respeito à credibilidade entre pecuarista e frigorífico no que se refere à entrega de boi pelo pecuarista na data combinada e quanto ao pagamento do boi pelo frigorífico no valor estabelecido na compra. Ressalta-se que a amostra constou de empresas frigoríficas, sendo necessário em trabalhos futuros acrescentar as informações dos pecuaristas envolvidos na transação. Porém, ressalta-se a garantia de oferta pode decorrer da falta de opção por parte dos pecuaristas quanto à venda do boi, em mercados oligopsônicos.

Observou-se também que algumas empresas iniciaram um processo de verticalização da produção para trás, de modo a atender as exigências impostas pelos clientes europeus e para garantir a oferta na entressafra.

Assim, na relação do frigorífico com o fornecedor de boi, coexistem duas formas básicas de comercialização: a utilização do mercado e a verticalização.

Quanto à relação do frigorífico com o cliente interno, observou-se que a maioria dos frigoríficos não realiza contratos, o que pode tam- 
bém ser explicado pelo comportamento confiável entre as partes. O fato de haver pouca variação dos clientes a cada ano, sendo que estes, na maioria dos casos, sempre cumpre o combinado entre as partes, e o fato da maioria das vendas serem realizadas diariamente, leva-os ao estabelecimento de um compromisso confiável. Ressalta-se também que as incertezas quanto à venda da carne bovina ao cliente interno relacionadas ao ambiente econômico são consideradas na maioria baixas. Também as exigências dos clientes internos são menores que as dos externos, reduzindo-se a especificidade do ativo.

Dessa forma, apesar da maioria dos frigoríficos participarem de Programas de Novilho Precoce ou Alianças Mercadológicas, em que ambos estimulam a adoção de estruturas de governança mais restritas, continuam ainda a ter relações via mercado com fornecedores de boi e clientes internos, mesmo com o processo de diferenciação da carne bovina.

No que se refere à relação do frigorífico com o cliente europeu, constatou-se que há realização de contratos, que sob a ótica da ECT, é a forma mais eficiente de se governar esta transação, devido ao alto grau da especificidade da carne bovina e dos demais ativos envolvidos na sua produção, bem como se constatou que as incertezas quanto à venda carne bovina ao cliente europeu relacionadas ao ambiente econômico são na maioria médias.

No que diz respeito ao SISBOV, observou-se que problemas relacionados à sua implantação, que têm levado as organizações presentes no SAG a reivindicarem a alteração de determinadas regras, têm dificultado sua real adoção pelos pecuaristas.

Assim, apesar do aumento das exigências dos consumidores europeus terem alterado o ambiente institucional do bloco, verificou-se que as alterações na forma de governança das transações do SAG da carne bovina nacional ocorreram principalmente através do aumento da verticalização para trás das empresas frigoríficas, e não pela adoção de contratos formais entre elas e os pecuaristas, pois tanto antes de 1996, ano em que se iniciam os aumentos das exigências externas, como atualmente, continua-se tendo relações via mercado entre frigoríficos exportadores com os pecuaristas e com os clientes internos.

Ressalta-se que os frigoríficos exportadores são apenas um subgrupo da indústria frigorífica, e que desta forma, o estabelecimento de 
um comportamento confiável entre frigoríficos e os fornecedores de boi e frigoríficos e clientes internos pode não ocorrer para o restante do mercado.

\section{Referências bibliográficas}

BRASIL. Ministério da Agricultura, Pecuária e Abastecimento (MAPA). Sistema Alice. http://www.agricultura.gov.br/ (18 mar. 2004)

ESTADOS UNIDOS. Department of Agriculture (USDA). Data and statistics. http://www.fas.usda.gov (04 Mar 2005)

EUROPA. Comissão Européia. Atividades da UE. http://www.europa. eu.int (05 May 2004)

NORTH, D.C. The new institutional economics and development. St. Louis: Washington University, Economics Department, 1993. 11p. (Working paper) http://www.econwpa.wustl.edu.80/eps/eh/papers/9309/9309002.pdf (21 Jan. 2004)

PITELLI, M.M. Sistema agroindustrial brasileiro da carne bovina: análise do impacto das mudanças institucionais européias sobre a estrutura de governança. São Paulo, 2004, p.160. Dissertação de Mestrado. - Escola Superior de Agricultura “Luiz de Queiroz”, Universidade de São Paulo.

WILLIAMSON, O.E. Las instituciones económicas del capitalismo. México: Fondo de Cultura Económica, 1989. 435p.

ZYLBERSZTAJN, D. Economia da organizações. http://www.projetoe. org.br/vteams/ tele_01/ leitura_01.html (06 mar. 2004)

Recebido em abril de 2005 e revisto em dezembro de 2005 